\title{
Combined paclitaxel, cisplatin and fluorouracil therapy enhances ionizing radiation effects, inhibits migration and induces G0/G1 cell cycle arrest and apoptosis in oral carcinoma cell lines
}

\author{
SILVIA TAVEIRA ELIAS ${ }^{1}$, GABRIEL ALVARES BORGES ${ }^{1}$, DANIELA FORTUNATO RÊGO ${ }^{1}$, \\ LUIS FELIPE OLIVEIRA E SILVA ${ }^{2}$, SAMUEL AVELINO ${ }^{2}$, JOÃO NUNES DE MATOS NETO², \\ LUIZ ALBERTO SIMEONI ${ }^{1}$ and ELIETE NEVES SILVA GUERRA ${ }^{1}$
}

\author{
${ }^{1}$ Faculty of Health Sciences, Campus Darcy Ribeiro, University of Brasília; ${ }^{2}$ Center of High Complexity in Oncology, \\ University Hospital of Brasília, Brasília, Federal District 70910-900, Brazil
}

Received July 26, 2014; Accepted April 9, 2015

DOI: $10.3892 / \mathrm{ol} .2015 .3458$

\begin{abstract}
Although taxels (in particular paclitaxel), cisplatin and fluorouracil (TPF) chemotherapy has been approved for use in the treatment of head and neck squamous cell carcinoma (HNSCC), little is known with regard to the cellular mechanisms of this novel drug association. In order to investigate the reaction of cells to this novel treatment, the present study aimed to examine the cytotoxic effect of TPF in HNSCC cell lines in combination with irradiation, to analyze its effect on cell cycle progression and cell death, and to evaluate its ability to alter cell migration. An MTT assay was used to determine cell viability following TPF and cisplatin treatments in two human HNSCC cell lines (FaDu and SCC-9) and one keratinocyte cell line (HaCaT). The concurrent use of TPF or cisplatin and irradiation was also analyzed. Flow cytometric analysis was utilized to determine the cell cycle distribution and to verify the induction of apoptosis. The capacity of the drugs to alter oral cancer cell migration was also evaluated using a Transwell migration assay. The results indicated that TPF and cisplatin were cytotoxic to all cell lines, and enhanced the effects of ionizing radiation. FaDu cells were significantly more sensitive to the two treatments, and TPF was more cytotoxic than cisplatin for all cells. Flow cytometric analysis revealed that TPF increased the number of cells in G0/G1 phase in the SCC-9 cell line, and indicated apoptotic cell death. The results of the Transwell assay demonstrated that TPF inhibited migration in oral carcinoma cell lines. The results of the present study indicated that TPF functions in oral carcinoma cell
\end{abstract}

Correspondence to: Dr Eliete Neves Silva Guerra, Faculty of Health Sciences, Campus Darcy Ribeiro, University of Brasília, 201 Asa Norte, Brasília, Federal District 70910-900, Brazil E-mail: elieteneves@unb.br

Key words: head and neck squamous cell carcinoma, paclitaxel, cisplatin, fluorouracil, irradiation, apoptosis, cell cycle arrest, cell migration lines through the enhancement of ionizing radiation effects, inducing cell cycle arrest at G0/G1 and apoptosis, in addition to inhibiting migration.

\section{Introduction}

Head and neck squamous cell carcinoma (HNSCC) comprises tumors of the oral cavity, pharynx and larynx, and is a relatively common human cancer. When grouped together, oral and pharyngeal cancer represent the sixth most common type of cancer worldwide. In South America and the Caribbean, cancers of the mouth and pharynx rank fifth amongst males and sixth in females (1). A high incidence rate for oral and laryngeal cancer is observed in Brazil, with up to 20,000 novel cases reported annually (2). The most significant etiological factors in the development of HNSCC are cigarette smoking and alcohol consumption (3); however, high-risk human papillomavirus (HPV), particularly HPV-16, has also been recognized as an independent factor for a subset of HNSCC, and there is a marked association between HPV infection and tonsil carcinoma development (4).

Surgery is the most well-established initial treatment strategy for the majority of oral cancers, however, radiotherapy may be employed in conjunction with surgery (5). In order to enhance organ preservation and survival, a multidisciplinary approach is encouraged, and concurrent chemo-radiotherapy has been recommended (6). Currently, due to the improvements in locoregional control, chemo-radiotherapy with cisplatin or other platinum compounds is considered to be a standard treatment regimen for patients with locoregionally advanced HNSCC. However, treatment with this combination is only successful in 50-60\% of patients. Thus, a novel and more effective management strategy with favorable toxicity levels is required (7).

A number of trials have indicated that a three-drug regimen consisting of a taxel (including docetaxel), cisplatin and 5-fluorouracil (TPF) improves the outcome of patients with HNSCC (8-10). These trials demonstrated that patients who underwent TPF induction chemotherapy combined with radiotherapy had a significantly longer survival compared with 
that of patients treated with cisplatin and fluorouracil (PF) plus radiotherapy (8). Compared with the standard $\mathrm{PF}$ regimen, induction chemotherapy with the addition of docetaxel significantly improved progression-free and overall survival in patients with unresectable HNSCC (10). Based on these data, in 2007, the Food and Drug Association (FDA) approved the use of docetaxel in combination with cisplatin and fluorouracil for the induction treatment of patients with locally advanced HNSCC (11).

Despite the FDA-approval of TPF for HNSCC treatment, little has been established with regard to the cellular mechanisms of action underlying this drug association. Based on the aforementioned findings and to further understand how cells react to this novel HNSCC treatment, the present study examined the cytotoxic effects of TPF in human HNSCC cell lines in association with irradiation, analyzed its effect on cell cycle progression and cell death, and evaluated its capacity to alter cell migration.

\section{Materials and methods}

Cell lines and culture conditions. Two human HNSCC cell lines were used in the present study: The tongue carcinoma cell line SCC-9, and the hypopharyngeal carcinoma cell line FaDu. A keratinocyte cell line (HaCaT) was used as a control. All cells were provided by Dr. Décio dos Santos Pinto Júnior (Faculty of Dentistry, University of São Paulo, São Paulo, Brazil). FaDu and HaCaT cells were cultured in Dulbecco's modified Eagle's medium (DMEM) supplemented with $10 \%$ fetal bovine serum and $1 \%$ antibiotics (penicillin-streptomycin). SCC-9 cells were cultured in a combination of DMEM and Ham's F12 (1:1 ratio), supplemented with hydrocortisone, $10 \%$ fetal bovine serum and $1 \%$ penicillin-streptomycin. Cells were maintained at $37^{\circ} \mathrm{C}$ in an atmosphere of $5 \% \mathrm{CO}_{2}$. For all experiments, cells were detached from the growth surface using trypsin $(0.25 \%)$ /EDTA $(1 \mathrm{mM})$ solution. All cell culture reagents were purchased from Sigma-Aldrich (St. Louis, MO, USA).

Drug preparation. Paclitaxel (6 mg/ml; Laboratório Químico Farmacêutico Bergamo Ltda., São Paulo, Brazil), cisplatin (Citoplax, $1 \mathrm{mg} / \mathrm{ml}$; Laboratório Químico Farmacêutico Bergamo Ltda.) and 5-fluorouracil (Fluoracila, $50 \mathrm{mg} / \mathrm{ml}$; Accord Farmacêutica Ltda., São Paulo, Brazil), designated TPF, were diluted in Milli-Q water at a ratio of 1:20:40, respectively, to obtain a $500 \mathrm{mg} / \mathrm{ml}$ stock solution (12). Fresh stock solutions were produced for each experiment. Final dilutions of $25,50,100$ and $200 \mu \mathrm{g} / \mathrm{ml}$ were used in the treatment of cells. Cisplatin alone was used in all experiments as a control, and in order to compare its cytotoxic effect with that of TPF.

Dose-response cytotoxicity of TPF. For the cytotoxicity experiment, FaDu, SCC-9 and HaCaT cells were seeded at a density of $5 \times 10^{3}$ cells/well into 96 -well plates, and incubated overnight at $37^{\circ} \mathrm{C}$ in $5 \% \mathrm{CO}_{2}$. Cells were then treated with serial dilutions of TPF or cisplatin alone in decreasing concentrations (200, 100, 50 and $25 \mu \mathrm{g} / \mathrm{ml}$ ), or with a vehicle control (culture medium). Following $24 \mathrm{~h}$ of treatment, $10 \mu \mathrm{l} \mathrm{MTT}(5 \mathrm{mg} / \mathrm{ml}$; Sigma-Aldrich) solution was added to each well, prior to incubation for $4 \mathrm{~h}$ at $37^{\circ} \mathrm{C}$. Following incubation, the treatment media were discarded, and $100 \mu \mathrm{l}$ isopropanol containing 5\% $1 \mathrm{M} \mathrm{HCl}$ solution was added to dissolve the formazan crystals. The absorbance was measured at $570 \mathrm{~nm}$ with a Beckman Coulter DTX 800 reader (\#987920; Beckman Coulter, Brea, CA, USA).

TPF and irradiation cytotoxicity assay. In order to evaluate the cytotoxicity of concurrent TPF or cisplatin and irradiation treatment, cells were seeded into 96-well culture plates at a density of $5 \times 10^{3}$ cells/well, incubated overnight at $37^{\circ} \mathrm{C}$ in $5 \% \mathrm{CO}_{2}$, and treated with the drug solutions at a concentration of $50 \mu \mathrm{g} / \mathrm{ml}$ for $24 \mathrm{~h}$. Following 24-h treatment, the medium was removed from the cells and $100 \mu \mathrm{l}$ PBS was added prior to irradiation. The irradiation was conducted using a Siemens PRIMUS linear accelerator, with $6 \mathrm{MV}$ photon beams at a dose rate of $2.0 \mathrm{~Gy} / \mathrm{min}$. As controls, one plate was treated only with radiation, and another was seeded and not irradiated. Immediately following irradiation, phosphate-buffered saline (PBS) was removed, and cells were maintained in culture medium without drug treatment. At 24 and $48 \mathrm{~h}$ after irradiation, cell death was assessed by MTT assay, and absorbance was measured at $570 \mathrm{~nm}$ using the DTX 800 reader.

Flow cytometric analysis. Flow cytometric analysis was performed to define the cell cycle distribution and induction of apoptosis in TPF- and cisplatin-treated and untreated cells. To determine the cell cycle distribution, cells were seeded into six-well plates at a density of $10^{6}$ cells/well and incubated overnight. Following $24 \mathrm{~h}$ of incubation, cells were treated with TPF or cisplatin at a concentration of $50 \mu \mathrm{g} / \mathrm{ml}$ for $6 \mathrm{~h}$, prior to the collection of floating and adherent cells, which were fixed in cold $70 \%$ ethanol for $30 \mathrm{~min}$, centrifuged at $537.6 \mathrm{x}$ g for $5 \mathrm{~min}$, washed with $1 \mathrm{ml}$ cold PBS and centrifuged again at $537.6 \mathrm{x} \mathrm{g}$ for $5 \mathrm{~min}$. The pellet was subsequently resuspended in $100 \mu \mathrm{l}$ of RNAse A $(250 \mu \mathrm{g} / \mathrm{ml})$ and incubated for $30 \mathrm{~min}$. Propidium iodide solution $(50 \mu \mathrm{g} / \mathrm{ml})$ was then added, followed by incubation in a dark chamber for $10 \mathrm{~min}$. Cells were analyzed with a Cyflow Space-9 flow cytometer (excitation, 488 nm; Sysmex Partec GmbH, Görlitz, Germany), with fluorescence measured at $620-640 \mathrm{~nm}$. A minimum of 10,000 events were analyzed and the distribution of cells in each phase of the cell cycle was determined.

Induction of apoptosis was assessed using flow cytometric analysis of outer membrane phosphatidylserine translocation. For this assay, a fluorescein isothiocyanate (FITC)-Annexin V/Dead Cell Apoptosis kit (Invitrogen Life Technologies, Carlsbad, CA, USA) was used. Cells were plated and treated with TPF and cisplatin as described for the cell cycle assay above. Following $6 \mathrm{~h}$ of treatment, the supernatant and cells were collected, centrifuged at $537.6 \mathrm{x} \mathrm{g}$ for $5 \mathrm{~min}$ and resuspended in $1 \mathrm{X}$ Annexin-binding buffer. FITC-Annexin V $(5 \mu \mathrm{l})$ and $1 \mu \mathrm{l}$ propidium iodide $(100 \mu \mathrm{g} / \mathrm{ml})$ were added to $100 \mu \mathrm{l}$ cell suspension. Following $15 \mathrm{~min}$ of incubation, stained cells were analyzed by flow cytometry using the FL1, FL2 and FL3 channels, and the percentages of apoptotic, late apoptotic and necrotic cells were identified.

Transwell migration assay. The capacity of TPF and cisplatin to alter human oral cancer cell migration was assessed using a Transwell migration assay. The $6.5 \mathrm{~mm}$ Costar ${ }^{\circledR}$ Transwell 
Table I. Percentage of viable cells relative to controls (determined by MTT assay) following 24 and $48 \mathrm{~h}$ treatments with various combinations of cisplatin $(50 \mu \mathrm{g} / \mathrm{ml}), \mathrm{TPF}(50 \mu \mathrm{g} / \mathrm{ml})$ and irradiation, in head and neck squamous cell carcinoma or HaCaT cells

\begin{tabular}{lccc}
\hline & & \multicolumn{2}{c}{ Viable cells, $\%$} \\
\cline { 2 - 4 } Treatment & FaDu & SCC-9 & HaCaT \\
\hline Control & 100 & $100^{\mathrm{a}}$ & $100^{\mathrm{a}}$ \\
Cisplatin 24 h & $41.66 \pm 9.60^{\mathrm{a}}$ & $70.00 \pm 4.96^{\mathrm{ab}}$ & $56.00 \pm 7.27^{\mathrm{ab}}$ \\
TPF 24 h & $38.62 \pm 10.15^{\mathrm{a}}$ & $58.61 \pm 6.84^{\mathrm{ab}}$ & $46.07 \pm 8.91^{\mathrm{ab}}$ \\
Radiotherapy 24h & $99.90 \pm 0.00$ & $93.50 \pm 0.67$ & $220.10 \pm 11.10$ \\
Radiotherapy 48 h & $102.30 \pm 0.22$ & $85.40 \pm 1.35$ & $190.50 \pm 8.41$ \\
Cisplatin + radiotherapy 24 h & $15.15 \pm 15.07^{\mathrm{a}}$ & $20.74 \pm 14.08^{\mathrm{a}}$ & $27.78 \pm 12.83^{\mathrm{ac}}$ \\
Cisplatin + radiotherapy 48 h & $11.03 \pm 15.80^{\mathrm{a}}$ & $28.31 \pm 12.74^{\mathrm{ab}}$ & $27.79 \pm 12.83^{\mathrm{ab}}$ \\
TPF + radiotherapy 24 h & $13.38 \pm 14.32^{\mathrm{a}}$ & $37.67 \pm 10.31^{\mathrm{a}}$ & $21.60 \pm 12.96^{\mathrm{a}}$ \\
TPF + radiotherapy 48 h & $13.34 \pm 14.33^{\mathrm{a}}$ & $19.24 \pm 13.35^{\mathrm{a}}$ & $1.41 \pm 11.34^{\mathrm{ac}}$ \\
\hline
\end{tabular}

Data are presented as the mean \pm standard deviation. ${ }^{\mathrm{a}} \mathrm{P}<0.05$ vs. control treatment; ${ }^{\mathrm{b}} \mathrm{P}<0.05 \mathrm{vs}$. FaDu cells; ${ }^{\mathrm{c}} \mathrm{P}<0.05 \mathrm{vs}$. SCC-9 and FaDu cells, Kruskal-Wallis, Mann-Whitney. TPF, paclitaxel + cisplatin + fluorouracil.

A

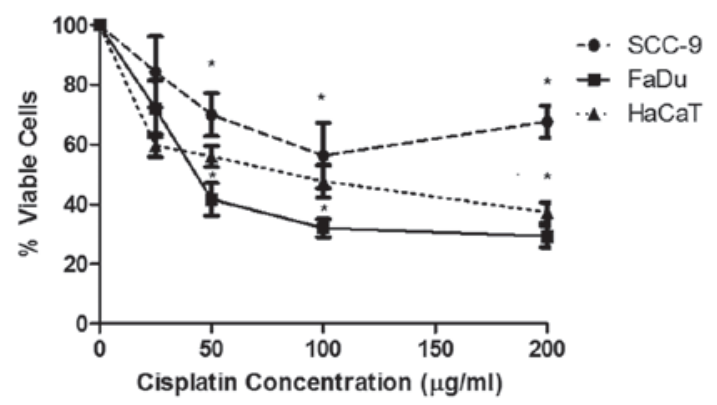

B

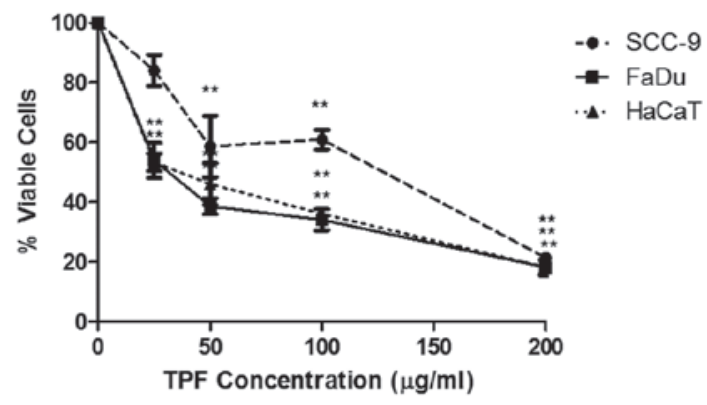

Figure 1. TPF and cisplatin induce a dose-dependent decrease in SCC-9, FaDu and HaCaT cell viability. Dose-response curves of the cells (SCC-9, closed circles; FaDu, closed squares; and HaCaT, closed triangles) treated for $24 \mathrm{~h}$ with (A) cisplatin and (B) TPF, at concentrations of $0,25,50,100$ and $200 \mu \mathrm{g} / \mathrm{ml}$. ${ }^{*} \mathrm{P}<0.05,{ }^{* *} \mathrm{P}<0.0001$ vs. control group. These results are representative of at least three independent experiments and are presented as the mean \pm standard deviation of triplicate experiments. TPF, paclitaxel + cisplatin + fluorouracil.

chambers (Corning Life Sciences, Cambridge, MA, USA), with polycarbonate membrane inserts $(8-\mu \mathrm{m}$ pore size), were placed in 24-well plates containing $600 \mu 1 \mathrm{DMEM}$ per well. Cells $\left(2 \times 10^{4}\right.$ per chamber) were seeded onto the upper compartment of each chamber and incubated at $37^{\circ} \mathrm{C}$ for $24 \mathrm{~h}$. Following this period, cells were treated with TPF or cisplatin at a concentration of $50 \mu \mathrm{g} / \mathrm{ml}$; PBS was used as a negative control. At $72 \mathrm{~h}$ after treatment, the cells that had migrated through the membrane to the lower compartment were fixed in methanol for $20 \mathrm{~min}$, incubated with $0.2 \%$ violet crystal dye for $5 \mathrm{~min}$ and washed with PBS 7-10 times. Following the final wash, the stained cells were viewed under a light microscope (Primovert; Zeiss, Göttingen, Germany) equipped with a digital camera (Axiocam ERc 5s; Zeiss) and photomicrographs from three randomly selected fields were captured at $\mathrm{x} 4$ magnification, in order to count the number of migrated cells using the image analysis ZEN 2012 software, blue edition (Carl Zeiss Microscopy GmbH, Göttingen, Germany).

Statistical analysis. Statistical analysis was performed using the mean values obtained in triplicate, from three indepen- dent replications of each experiment. The values obtained from the MTT assay were transformed into percentages representing the inhibitory effect of the treatments on cellular mitochondrial activity, compared with the negative controls (considered to represent $100 \%$ cell metabolic activity). For the MTT assay, statistical analyses were performed using SPSS version 21 (IBM SPSS, Armonk, NY, USA) and applying the Kruskal-Wallis and Mann-Whitney non-parametric tests. For flow cytometric analysis, data were analyzed with GraphPad Prism (GraphPad Software, Inc., La Jolla, CA, USA) using a one-way analysis of variance with Dunnett's post hoc test. $\mathrm{P}<0.05$ was considered to indicate a statistically significant difference.

\section{Results}

TPF reduces viability of FaDu, SCC -9 and $\mathrm{HaCaT}$ cells. Cisplatin and TPF regimens were cytotoxic to all cell lines, however, there was no statistically significant difference between TPF and cisplatin (Table I). Cisplatin induced increasing toxicity up to a concentration of $100 \mu \mathrm{g} / \mathrm{ml}$, exerting 
a clear dose-dependent response (Fig. 1A). The higher concentration, $200 \mu \mathrm{g} / \mathrm{ml}$, did not result in a significant reduction in viability compared with that of $100 \mu \mathrm{g} / \mathrm{ml}$ in the tested cells. Therefore $100 \mu \mathrm{g} / \mathrm{ml}$ was selected as the maximum concentration to be used in these cell lines. TPF treatment resulted in a regular dose-response curve and produced a considerable reduction in cell viability at $200 \mu \mathrm{g} / \mathrm{ml}(\mathrm{P}<0.001$ compared with $0 \mu \mathrm{g} / \mathrm{ml}$ ) in all cell lines, even though this concentration was notably aggressive to the keratinocyte cell line, causing loss of cellular integrity and sharpness. In SCC-9 cells, TPF demonstrated greater cytotoxicity. At $50 \mu \mathrm{g} / \mathrm{ml}$, TPF was able to induce a viability reduction of $\sim 42 \%$, and at the maximum concentration, this reduction reached $78 \%$ (Fig. 1B). Treatment with cisplatin alone reduced cell viability by only $43 \%$ at a concentration of $100 \mu \mathrm{g} / \mathrm{ml}$. For HaCaT cells, the two treatment regimens were found to be aggressive: TPF and cisplatin were able to reduce cell viability by almost 54 and $43 \%$, respectively, at a concentration of $50 \mu \mathrm{g} / \mathrm{ml}$. These results confirmed that the chemotherapy regimen currently used in the treatment of head and neck cancer is not selective for tumor cells.

Table I shows that TPF was more cytotoxic than cisplatin in the FaDu and SCC-9 cell lines, however, this difference was not statistically significant. The two chemotherapy regimens were significantly more cytotoxic in FaDu cells, compared with SCC-9 cells $(\mathrm{P}<0.001$ for cisplatin and TPF at $100 \mu \mathrm{g} / \mathrm{ml}$ ). These results demonstrated that, although all cells have the same origin, cells from hypopharyngeal carcinoma are more sensitive to chemotherapy.

A concentration of $50 \mu \mathrm{g} / \mathrm{ml}$ induced a cell viability reduction of 50\% for all cell lines with the two chemotherapy regimens, and was therefore selected for use in the radiotherapy experiment.

Treatment with TPF improves cellular response to irradiation. Treatment with irradiation alone at $2 \mathrm{~Gy} / \mathrm{min}$, the dose used for clinical application in patients, was not cytotoxic for HNSCC cell lines and induced proliferation in keratinocytes (Table I). Chemo-radiotherapy led to higher cytotoxicity compared with that of each treatment method alone. Radiotherapy following treatment with TPF ( $48 \mathrm{~h}$ subsequently) and cisplatin (24 h subsequently) was significantly less cytotoxic to keratinocytes than to cancer cells $(\mathrm{P}<0.05)$. The results also revealed that irradiation following $48 \mathrm{~h}$ of pretreatment with TPF produced enhanced cytotoxicity for SCC-9 cells (19.24\% viable cells), and with cisplatin for $\mathrm{FaDu}$ cells $(11.03 \%$ viable cells), compared with control cells $(100 \%$ viable cells). Together, these results suggested that combined TPF and radiotherapy may be an effective strategy for the treatment of oral cancer with reduced toxicity in the HaCaT cells compared with cancer cells.

TPF induces G0/G1 cell cycle arrest and enhances apoptosis. To further determine whether TPF and cisplatin inhibited cell proliferation by induction of cell cycle arrest, HNSCC cells were exposed to the two treatments at $50 \mu \mathrm{g} / \mathrm{ml}$ for $6 \mathrm{~h}$ and cell-cycle distribution was evaluated by flow cytometric analysis. Cisplatin and TPF treatments induced partial G0/G1 cell cycle arrest in SCC-9 cells, however, only TPF treatment resulted in a statistically significant effect (Fig. 2; $\mathrm{P}<0.05$ ).

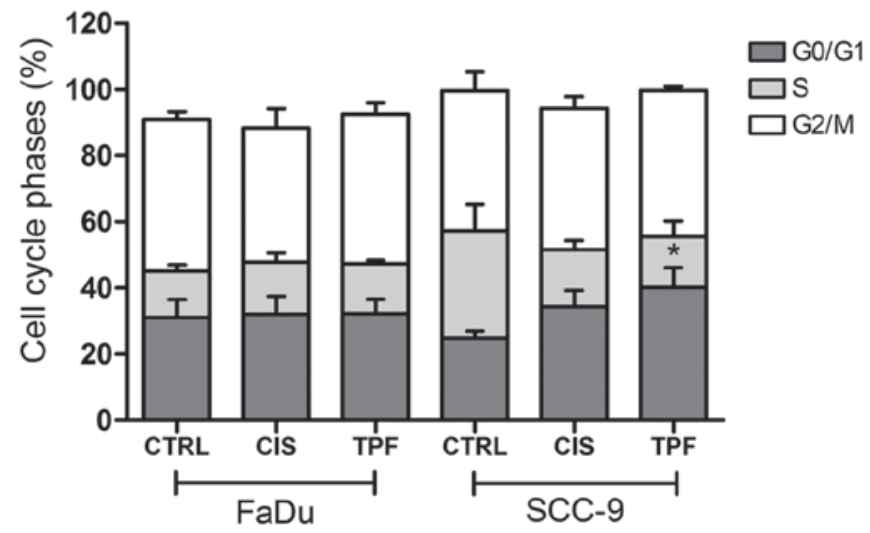

Figure 2. TPF induces partial G0/G1 cell cycle arrest. Flow cytometry indicating the cell cycle distribution of FaDu and SCC-9 cells following $6 \mathrm{~h}$ of treatment with TPF and CIS. " $\mathrm{P}<0.05$ vs. CTRL. Results are representative of three independent experiments and are presented as the mean \pm standard deviation. TPF, paclitaxel + cisplatin + fluorouracil; CIS, cisplatin; CTRL, control.

For FaDu cells, no difference was observed between treated and control cells, and the distribution of cells in each phase of the cycle remained constant following $6 \mathrm{~h}$ of treatment.

SCC-9 cells exhibited considerable changes in the cell cycle when treated with one of the two regimens: Cisplatin and TPF enhanced the percentage of cells in G0/G1 phase compared with that of controls. A greater proportion of cells were found to be in phase G0/G1 following TPF treatment (40\%) compared with the control group (22\%), and this difference was statistically significant $(\mathrm{P}<0.05)$. Additionally, a decrease in the percentage of cells in $\mathrm{S}$ phase was observed, (15\% of TPF-treated cells, compared with $33 \%$ of control cells). The proportion of cells in phase $\mathrm{G} 2 / \mathrm{M}$ remained stable. The results of this experiment confirmed that the treatment with TPF reduces the number of cells in the mitotic phase (Fig. 2).

Induction of apoptosis was also assessed using flow cytometric analysis, which revealed that treatment with TPF significantly increased cell death, as indicated by Annexin staining (FL1 channel), while TPF and cisplatin markedly reduced cell migration in SCC-9 cells $(\mathrm{P}<0.001)$. At $6 \mathrm{~h}$ following treatment, the rate of apoptosis was observed to be $12.80 \%$ (TPF), $5.39 \%$ (cisplatin) and $4.48 \%$ (control) in SCC-9 cells (Fig. 3A).

In FaDu cells, cisplatin and TPF induced similar rates of cell death. Annexin events occurred more frequently with cisplatin, inducing a rate of apoptosis of $3.55 \%$ compared with $1.39 \%$ following TPF treatment (Fig. 3B). Staining with propidium iodide (FL2 channel) was observed following TPF and cisplatin treatment in $7.89 \%$ and $3.63 \%$ of events, respectively (Fig. 3B).

TPF reduces cell migration ability of HNSCC cells. Data from the Transwell assay following TPF and cisplatin treatment are presented in Fig. 4. Comparison between treated and control cells revealed that TPF and cisplatin markedly decreased cell migration in SCC-9 cells. A decrease in migration of 95.34 and $90.67 \%$ was observed following TPF and cisplatin treatments, respectively. 
A

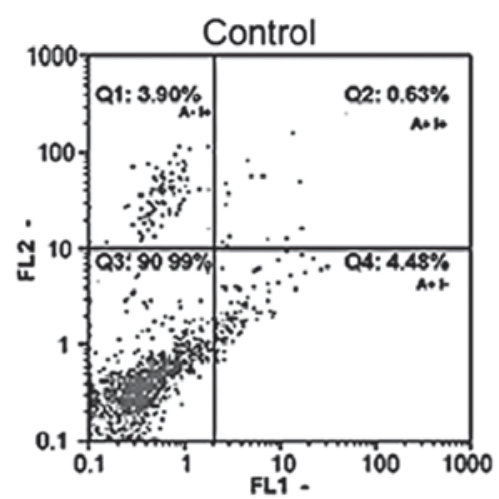

B

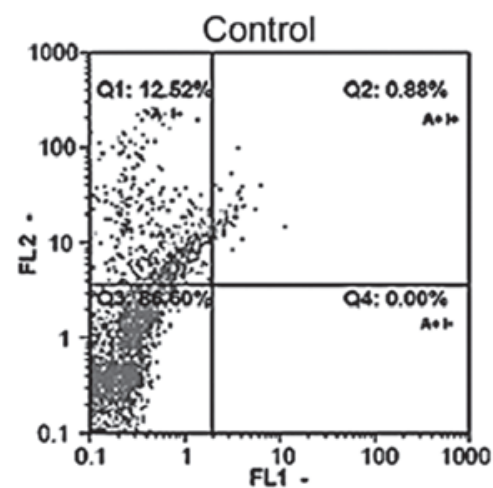

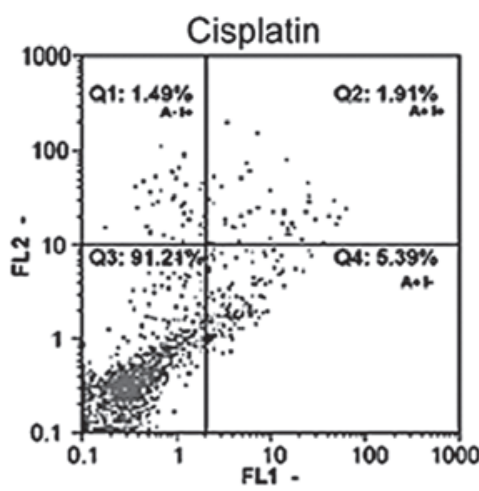
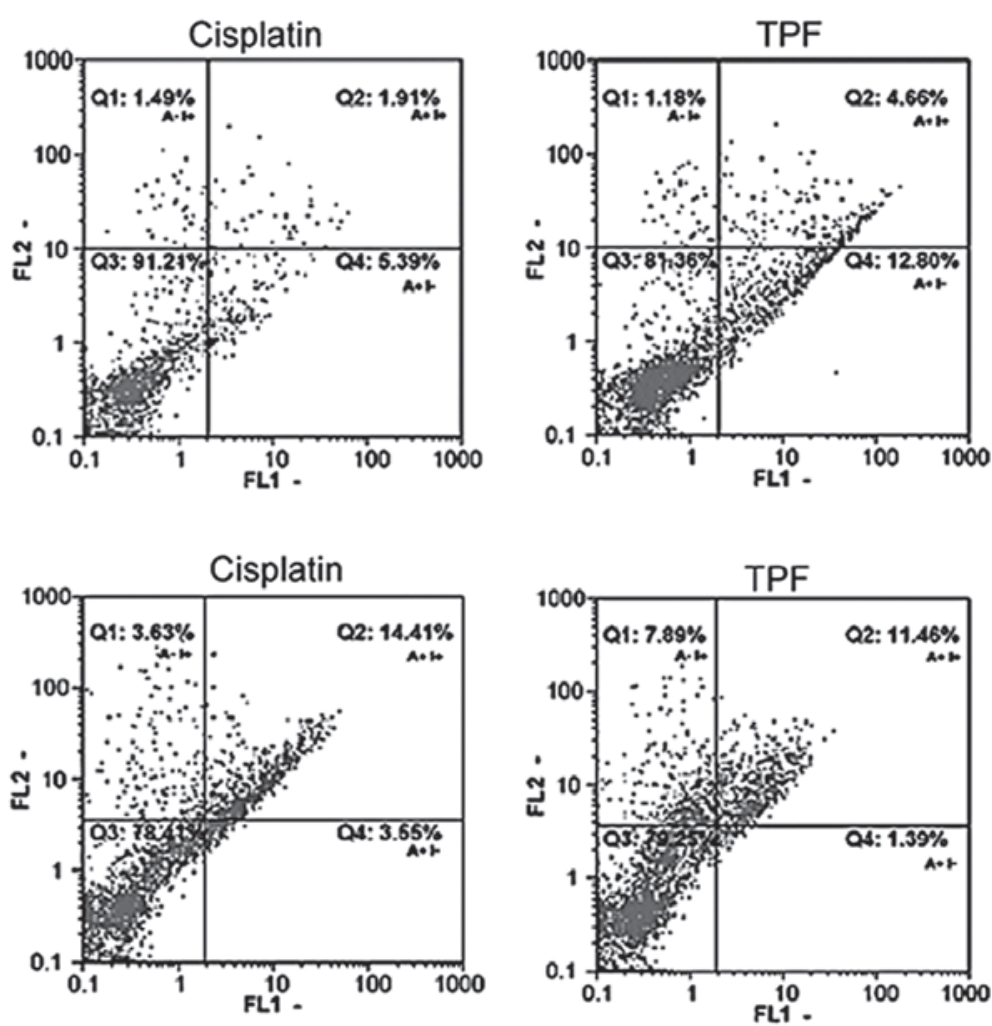

Figure 3. TPF treatment significantly enhances cell apoptosis. Effects of cisplatin and TPF at $50 \mu \mathrm{g} / \mathrm{ml}$ in (A) SCC-9 and (B) FaDu cells following 6 h of treatment. FL1 channel represents cells staining for Annexin and FL2 propidium iodide. Cells in the lower right quadrant represent early apoptosis, cells in the upper right quadrant represent late apoptosis and cells in the upper left quadrant show necrosis. TPF, paclitaxel + cisplatin + fluorouracil.

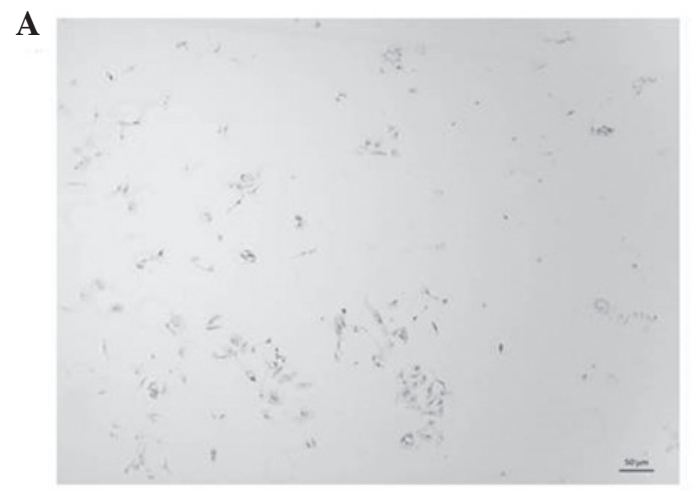

C

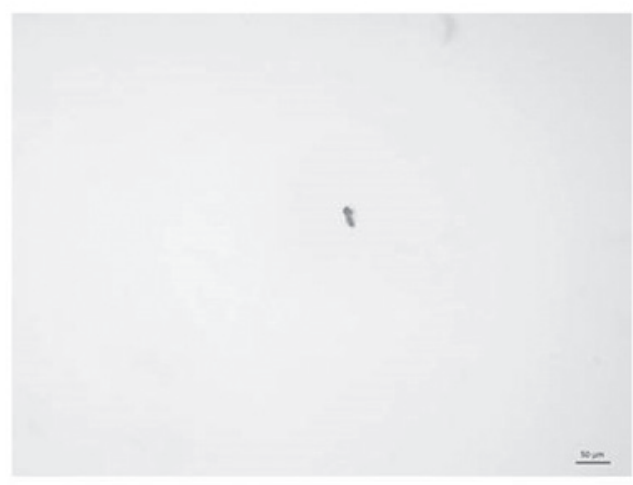

B

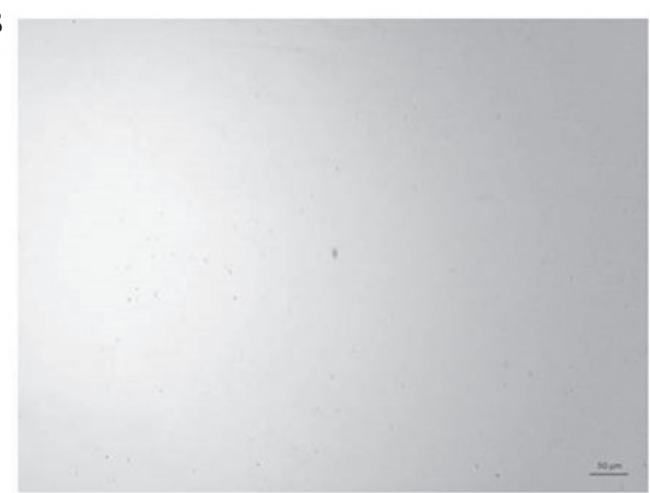

D

scc-9

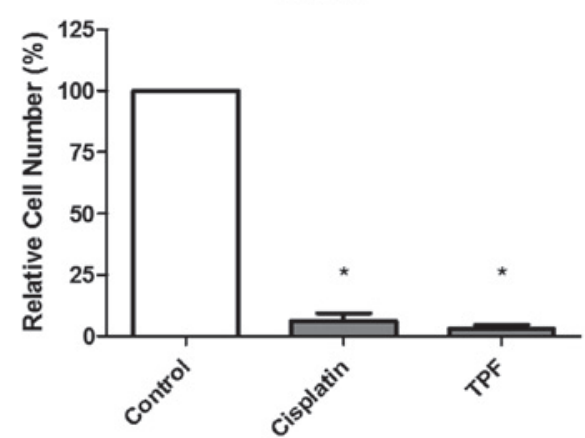

Figure 4. TPF and cisplatin treatment decrease cell migration ability. Photomicrographs of migrated cells in the lower chambers and cell counting following Transwell assay. Cells were seeded in the upper chambers and treated with TPF or cisplatin. Following $72 \mathrm{~h}$ of treatment, cells which had migrated through the membrane were stained with crystal violet. (A) SCC-9 control cells, (B) SCC-9 cells treated with TPF and (C) SCC-9 cells treated with cisplatin. (D) Cells from two random fields in each photomicrograph were counted. Treated cells were compared with the control group, which was considered to be $100 \%$. ${ }^{*} \mathrm{P}<0.0001$ vs. control group. Results are presented as the mean \pm standard deviation of cell count in different fields. TPF, paclitaxel + cisplatin + fluorouracil. 


\section{Discussion}

The role of concurrent chemo-radiation in the treatment of HNSCC has previously been established and validated, and cisplatin-based chemotherapy remains the current standard treatment strategy (13). The discovery of cisplatin as an anti-cancer drug in the 1960s marked a novel era for cancer treatment. Cisplatin is able to induce cytotoxicity, dependent upon on cell type and drug concentration; this may occur via interference with transcription and/or DNA replication mechanisms. Cisplatin may also act to induce apoptosis of tumor cells, an effect which is mediated via the activation of various signal transduction pathways, including calcium and death receptor signaling, in addition to activation of mitochondrial pathways. However, cytotoxicity and apoptosis are not induced exclusively in cancer cells. Cisplatin also induces diverse side-effects, for example neural and renal toxicity or bone marrow-suppression. To minimize cisplatin resistance, combinatorial therapies have been developed, which have been demonstrated to exert greater efficacy in the treatment of cancer (14).

In September 2007, the FDA approved docetaxel for use in combination with cisplatin and fluorouracil for the induction treatment of patients with locally advanced HNSCC (11). However, the cellular mechanisms and the cytotoxic effect of this novel drug combination have remained unclear. Thus, the objective of the present study was to compare the effects of cisplatin monotherapy with a novel combination regimen of paclitaxel, cisplatin and 5-fluorouracil in head and neck cancer cells. In addition, the cellular mechanisms of these drugs and their effect on the cell cycle and cell death were analyzed.

The results revealed that $\mathrm{FaDu}$ cells, derived from hypopharyngeal cancer, were more sensitive to all treatments than SCC-9 cells, derived from tongue cancer. Although oral cancer and hypopharyngeal cancer have identical epidermal origins, they behave differently and, therefore exhibit differential reactions to the treatments to which they are subjected. Clinical evidence indicates that oral cancer is more aggressive and has a poorer response to treatment compared with hypopharyngeal cancer (15). This evidence was confirmed by the results of the present study.

$\mathrm{TPF}$ treatment produced greater cytotoxic effects in $\mathrm{FaDu}$ and SCC-9 cells compared with that of cisplatin treatment, however, this difference was not statistically significant. Based on these findings, the two treatments provide viable treatment options for consideration in HNSCC.

Cells treated with a single dose of radiation $(2 \mathrm{~Gy} / \mathrm{min})$ exhibited no significant damage and cell viability was unaffected; notably, proliferation was observed in keratinocytes. Previous studies have identified similar responses when head and neck cancer cells were subjected to a single dose of irradiation $(7,16)$. It has been reported that exposure of cells to a single dose of irradiation may induce sublethal damage, which is insufficient to induce apoptosis (16). In order to induce cell death, a greater number of doses of irradiation, or a combination of therapies is required. Chemotherapy regimens in combination with radiation treatment enables enhanced cell cytotoxicity compared with that of chemotherapy or radiation alone for head and neck cancer cells, as demonstrated by the present cytotoxicity assays. To the best of our knowledge, the results of the present study demonstrate, for the first time in vitro, the supra-additive effect of irradiation and TPF (in the respective ratio of 1:20:40) for HNSCC. Although none of the treatments proposed were selective for the cancer cell lines assessed, the combination of TPF $48 \mathrm{~h}$ following irradiation, was significantly less cytotoxic to keratinocyte cells (HaCaT) than to cancer cells $(\mathrm{P}<0.05)$, which indicated that this therapy may result in fewer side effects for patients undergoing cancer treatment. Thus the combined treatment of TPF plus radiotherapy may present a more favorable option of treatment for hypopharyngeal and tongue cancer, compared with the $48 \mathrm{~h}$ cisplatin with irradiation.

To further determine whether TPF and cisplatin inhibited cell proliferation by induction of cell cycle arrest, $\mathrm{FaDu}$ and SCC-9 cells were exposed to the two regimens for $6 \mathrm{~h}$, prior to the evaluation of cell cycle distribution by flow cytometric analysis. TPF treatment resulted in partial G0/G1 cell cycle arrest only in SCC-9 cells, and the number of cells in G0/G1 phase increased following each of the treatments, however, the results were only statistically significant for TPF treatment (Fig. 2). Cell cycle analysis revealed that TPF induced G0/G1 cell cycle arrest in oral cancer cells; further studies are necessary to identify which proteins were modified by the treatment. Cyclin D1 is often amplified and over-expressed in a variety of tumors, including HNSCC. Decreased levels of cyclin D1 may be responsible for the G1 cell cycle arrest and growth inhibition induced by TPF treatment. A recent phase III trial evaluated standard treatment comprised of surgery and postoperative radiotherapy, with and without prior induction TPF. Subsequent immunohistochemical staining for cyclin D1 revealed that the nodal stage $\mathrm{cN} 2$ patients (whose tumors were found to highly express cyclin D1), had significantly greater overall survival and distant metastasis-free survival when treated with TPF (17).

It has been established that apoptotic pathways are deregulated in cancer (18), therefore the induction of apoptotic and/or necrotic cell death in HNSCC lines may represent a promising antineoplastic therapy. Using flow cytometric analysis, the present study observed that TPF and cisplatin induced apoptosis and necrosis in the two cell lines. It was more significant, however, when SCC-9 cells were treated with TPF. This indicated that TPF induces oral cancer cell death by apoptosis. Bozec et al (19) demonstrated that combined treatments of TPF/cetuximab or TPF/cetuximab/bevacizumab significantly reduced tumor volume and had a significant impact on the histological response in an orthotopic head and neck cancer model. Ki67 is a nuclear protein expressed in proliferating cells and is preferentially expressed during late G1, S, M or G2 phases of the cell cycle, while cells in the quiescent phase are negative for this protein. Thus, a reduction in Ki67 labeling indicates a reduction in the number of proliferating cells. Treatment with TPF and combinations decreased Ki67 labeling and $\mathrm{B}$ cell lymphoma $2(\mathrm{Bcl} 2)$ expression, indicating that $\mathrm{Bcl} 2$ may be downregulated in oral cancer cells treated with TPF.

An understanding of the process by which tumor cells destroy the basement membrane of the surface epithelium, in addition to invasion and metastasis, is required for the development of novel treatments for HNSCC. The epithelial to mesenchymal transition is a dynamic cellular process that is fundamental to the development of metastatic disease $(20,21)$. 
Through the Transwell assay, it was demonstrated that the migratory abilities of SCC-9 cells treated with $50 \mu \mathrm{g} / \mathrm{ml}$ of TPF or cisplatin was decreased by 95.34 and $90.67 \%$, respectively. To the best of our knowledge, this is the first study to show that TPF inhibits migration of oral squamous cell carcinoma (OSCC) cells in vitro, suggesting that it is an important chemotherapic agent for reducing the invasion and metastasis of OSCC.

In conclusion, these present findings highlight certain cellular mechanisms induced by TPF in HNSCC cells, including the inhibition of cell migration and the induction of G0/G1 cell cycle arrest and apoptosis in oral cancer cell line. Furthermore, TPF inhibits cell viability and enhances the effects of ionizing radiation in head and neck cancer cell lines.

\section{Acknowledgements}

The authors would like to thank Dr André Ferreira Leite (Dental Clinic, University Hospital of Brasília, Brasília, Brazil) for his assistance with the statistical analysis.

\section{References}

1. Warnakulasuriya S: Global epidemiology of oral and oropharyngeal cancer. Oral Oncol 45: 309-316, 2009.

2. Instituto Nacional de. Câncer: Brazilian cancer incidence. www. inca.gov.br/estimativa/2014. Accessed February 15, 2014.

3. Warnakulasuriya S: Causes of oral cancer - an appraisal of controversies. Br Dent J 207: 471-475, 2009.

4. Thavaraj S, Stokes A, Guerra E, Bible J, Halligan E, Long A, Okpokam A, Sloan P, Odell E and Robinson M: Evaluation of human papillomavirus testing for squamous cell carcinoma of the tonsil in clinical practice. J Clin Pathol 64: 308-312, 2011.

5. Shah JP and Gil Z: Current concepts in management of ora cancer - surgery. Oral Oncol 45: 394-401, 2009.

6. Salama JK, Haddad RI, Kies MS, Busse PM, Dong L, Brizel DM, Eisbruch A, Tishler RB, Trotti AM and Garden AS: Clinical practice guidance for radiotherapy planning after induction chemotherapy in locoregionally advanced head-and-neck cancer. Int J Radiat Oncol Biol Phys 75: 725-733, 2009.

7. Zhang N, Erjala K, Kulmala J, Qiu X, Sundvall M, Elenius K and Grénman R: Concurrent cetuximab, cisplatin, and radiation for squamous cell carcinoma of the head and neck in vitro. Radiother Oncol 92: 388-392, 2009.
8. Posner MR, Hershock DM, Blajman CR, et al; TAX 324 Study Group: Cisplatin and fluorouracil alone or with docetaxel in head and neck cancer. N Engl J Med 357: 1705-1715, 2007.

9. Rapidis AD, Trichas M, Stavrinidis E, Roupakia A, Ioannidou G, Kritselis G, Liossi P, Giannakouras G, Douzinas EE and Katsilieris I: Induction chemotherapy followed by concurrent chemoradiation in advanced squamous cell carcinoma of the head and neck: Final results from a phase II study with docetaxel, cisplatin and 5-fluorouracil with a four-year follow-up. Oral Oncol 42: 675-684, 2006.

10. Vermorken JB, Remenar E, van Herpen C, et al; EORTC 24971/TAX 323 Study Group: Cisplatin, fluorouracil, and docetaxel in unresectable head and neck cancer. N Engl J Med 357: 1695-1704, 2007.

11. (NCI/NIH) NCI: FDA approval for docetaxel. www.cancer. gov/cancertopics/druginfo/fda-docetaxel. Accessed February 15, 2014.

12. Lim YC, Oh SY, Cha YY, Kim SH, Jin X and Kim H: Cancer stem cell traits in squamospheres derived from primary head and neck squamous cell carcinomas. Oral Oncol 47: 83-91, 2011.

13. Belcher R, Hayes K, Fedewa S and Chen AY: Current treatment of head and neck squamous cell cancer. J Surg Oncol 110: 551-574, 2014.

14. Florea AM and Büsselberg D: Cisplatin as an anti-tumor drug: Cellular mechanisms of activity, drug resistance and induced side effects. Cancers Basel 3: 1351-1371, 2011.

15. Leemans CR, Braakhuis BJ and Brakenhoff RH: The molecular biology of head and neck cancer. Nat Rev Cancer 11: 9-22, 2011.

16. Zheng XK, Chen LH, Wang WJ, Ye F, Liu JB, Li QS and Sun HW: Impact of prolonged fraction delivery times simulating IMRT on cultured nasopharyngeal carcinoma cell killing. Int J Radiat Oncol Biol Phys 78: 1541-1547, 2010.

17. Zhong LP, Zhu DW, William WN Jr, et al: Elevated cyclin D1 expression is predictive for a benefit from TPF induction chemotherapy in oral squamous cell carcinoma patients with advanced nodal disease. Mol Cancer Ther 12: 1112-1121, 2013.

18. Hanahan D and Weinberg RA: The hallmarks of cancer. Cell 100: 57-70, 2000.

19. Bozec A, Sudaka A, Etienne-Grimaldi MC, Brunstein MC, Fischel JL and Milano G: Antitumor activity of cetuximab associated with the taxotere-cisplatin-fluorouracil (TPF) combination on an orthotopic head and neck cancer model. Oral Oncol 47: 940-945, 2011.

20. Scanlon CS, Van Tubergen EA, Inglehart RC and D'Silva NJ: Biomarkers of epithelial-mesenchymal transition in squamous cell carcinoma. J Dent Res 92: 114-121, 2013.

21. Smith A, Teknos TN and Pan Q: Epithelial to mesenchymal transition in head and neck squamous cell carcinoma. Oral Oncol 49: 287-292, 2013. 